\title{
Patient Experience: A Key Instrument in Analyzing Patient Satisfaction in Public Hospitals in Chennai
}

\author{
Dhyana Sharon Ross ${ }^{1 *}$ and R. Venkatesh ${ }^{2}$ \\ 'VIT Business School Chennai, Chennai - 600127, Tamil Nadu, India; \\ dhyana.sharonross2014@vit.ac.in, \\ 2VIT University, Chennai - 600127, Tamil Nadu, India; \\ venkatesh.r@vit.ac.in
}

\begin{abstract}
Objective: Patient satisfaction is a widely used quality metric that has increasing importance in running hospitals successfully, especially for public hospitals, where patients are treated free of cost or at very low cost. While enhancing the nature of quality care is a universal test, sustaining the care quality is a paramount challenge. In this study data on patient an experience was collected as it can be used to target improvement of the care provided and for future research. Methods and Statistical Analysis: This study was conducted in 7 public hospitals in Chennai, India. Descriptive research design was used and results of ANOVA shows that patients are satisfied to an extent with their experience in those public hospitals in Chennai. Findings: The statistical analysis revealed that there is a significant relationship between patient satisfaction on their experiences in hospital and patient loyalty to the hospital as only satisfied patients are ready to recommend the hospitals for others. It also shows that only satisfied patients return to the hospitals for continuity of care and remain loyal to the hospital. Application: Positive patient experience helps the hospital to gain patient loyalty. While poor or bad experience dissatisfies the patient and stops them from using the services and recommending the hospital to others
\end{abstract}

Keywords: Healthcare Quality, Patient Experience, Patient Satisfaction, Recommendation.

\section{Introduction}

Since healthcare industry is changing rapidly, it is mandatory for the hospitals to focus on increasing patient satisfaction, by providing them with better experiences. The positive experience of the patient will induce revisit or will make the patients encourage others to visit the hospital. In a hospital, patient satisfaction scores display a constrained and hopeful picture of hospital's quality and about the delivery of healthcare success. Detailed inquiry about particular aspects of patient experiences is most useful features for overseeing the performances of various departments in hospitals and to point out the drawbacks so that delivery of healthcare can be improved in future for quality treatment?. Delivering quality care can put individuals, teams and organizations under pressure. Healthcare workers need to settle on troublesome choices in element and regularly amid unusual conditions. In such case, decision making is compromised, which impacts the quality of care. Treatment task, equipment, workspace culture and organization on human behavior are few factors that influence patient satisfaction and patient experiences: While other factors such as patient expectations, health status, and type of care and immunization coverage were also found to be important in determining patient satisfaction on healthcare delivery, patient experience was significantly associated with healthcare system and explained only $10 \%$ of variation around the concept of patient satisfaction. In spite of many improvements and initiatives in hospitals, delivering quality care remains open to numerous questions 5 - Patient experience and their satisfaction can be used to target improvement in delivering quality care and for future research Patients who have experienced hospitalization can provide unique insights into the quality of care, which can be used for hospital quality improvement. However not all the time patient experiences are used in hospital quality measurement and

* Author for correspondence 
quality improvement plan as the patients' experience data collected should be reliable and valid, yet usable in As a measurement of patient experiences has become a very important component of patients' satisfaction and health services evaluations, many countries have now programmed themselves to undertake patient surveys at regular intervals International level comparisons of patients' experiences are important for analyzing and identifying the areas, which needs change crosswise over hospital administrations. Identifying the recurring patterns of patient's experiences across the countries will help the healthcare organizations in knowing the chances to gain from national and worldwide endeavors to move forward in healthcare quality to gain patient satisfaction

Patient satisfaction is highly desirable outcome of the treatment received. Patients who have experienced this during their treatment time and stay in hospitals will be more adherent to treatment plans, will be loyal to their physicians, will probably keep utilizing healthcare services and recommend services to others ${ }^{13,1}$, Global correlations of patient encounters are essential, so that areas of improvement for healthcare services a can be identified between countries about patient experiences, will help in identifying opportunities to learn from

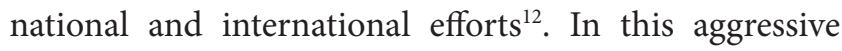
current social environment, medicinal services chiefs have been endeavoring hard to discover approaches to survive or exceed expectations with respect to other, by making comparative improvement and changes, based on patients' feedback and patient experiences, and many strategies for evaluating patient satisfaction mainly based on patient experiences ${ }^{15-1 / 2}$

\subsection{Patient Satisfaction}

Patient satisfaction is a pivotal indicator of quality of care provided to patient ${ }^{19,22}$. Satisfaction with the practitioner and continues the treatment星. Patient satisfaction can be defined as gap between the patient's perception of care received and the care they expected 2 . Patient satisfaction during hospitalization represents a balance between the patient perception and expectation of their quality care f $^{\text {, }}$ It is difficult to measure patient satisfaction in health systems and both clinical and non-clinical outcomes of care and its effects on patient experience influences patient satisfaction . Patient satisfaction is thought to an important measure by many in healthcare industry as patient is a highly desirable outcome of clinical care in hospital. Patient satisfaction plays a vital role in influencing care. Level of patient satisfaction and patient experience has major impact on patients treatment plans, patients' loyalty towards their physicians, continuation of health services and recommendation of hospital to others . Satisfaction with care and their positive experience has been linked to patient adherence to physician's recommendations and loyalty to physicians Patient satisfaction is a marker that captures interpersonal care experiences (such communication) that correlates with technical care, representing a unique dimension of quality. Patient satisfaction leads to increased patient engagement in medical care leads to lower resources utilization as well as increased satisfaction ${ }^{2}$.

\subsection{Patient Experiences with Healthcare Services}

Patients own service experiences of the administrations exhibitions is one significant dependent variable in the study of patient satisfaction. This factor creates one's hope of receiving the same and preferred nature of administrations over they get used to seeing, touching, listening, smelling and tasting are quality services elements on which patients generally base their judgments of the services received. On the off chance that a patient ceaselessly encounters same administrations with various methods for serving, patient opinion about quality services would be immediately changed Though earlier researches have addressed this earlier, patient satisfaction remain hard to be determined as it is a multi dimensional concept with different perspectives, which don't need to do with the genuine nature of care and administration experienced by the patient. One feedback of patient fulfillment appraisals in previous researches in that, there is an inability to account for expectation about the treatment, which might be impacted by related involvements with the healthcare systems 9 . Each patient possesses different experience as accordingly how their needs and expectations are met ${ }^{30,3}$.

\subsection{Positive Patient Experiences}

Patients usually compare the expected level of services with the provided services to see how much their expectations are met. The service quality thus is measured by positive criteria of whether an administration is all around given to meet client's desire. This influences positive patient experiences. It is essential for the correct understanding of service element for the effective delivery 
of medical services and high levels of patient satisfaction as the patient demand it through their experience $\beta^{\text {. }}$. When patient have high quality experiences, it reflects improved outcome, indicates good care and choices given to patients. There is evidence, that healthcare organizations with strong emphasis on achieving high-quality patient experience have found that patient experiences are linked to better health outcomes. Hospitals are able to improve services and highlight poor care, by understanding how patients experience care. Previous studies revealed that poor performance in related to patients' experience, their problems were acknowledged and solved. As patient choice remains a continued priority, patient experiences helps in responding to patient preferences leading to patient satisfaction 3 . The results of present study on patient satisfaction on patient experience have been tabulated (Table1). The study also explains about the positive relationships between gender and patient experience on information and education given in hospitals, gender and patient experience on coordination of care in hospitals, gender and patient experience on physical comfort in hospitals, age and patient experience on emotional support, age and patient experience on respect for patient preferences (Table 2-7).

Table 1. Descriptive statistics of variables

\begin{tabular}{lcc}
\hline Patient experience & Mean & $\begin{array}{c}\text { Standard } \\
\text { Deviation }\end{array}$ \\
\hline Information and education & 20.2393 & 3.183 \\
provided in hospital & 20.1795 & 3.199 \\
Coordination of care & 8.3846 & 0.828 \\
Physical comfort & 12.6325 & 1.095 \\
Emotional support & 8.1966 & 2.122 \\
Respect for patient preferences & 11.0684 & 2.762 \\
Continuity and transition & & \\
\hline
\end{tabular}

Table 2. Descriptive statistics of survey item

\begin{tabular}{llcc}
\hline $\begin{array}{l}\text { Patient } \\
\text { experience }\end{array}$ & Items & Mean & $\begin{array}{l}\text { Standard } \\
\text { deviation }\end{array}$ \\
\hline $\begin{array}{l}\text { Information and } \\
\text { education }\end{array}$ & $\begin{array}{l}\text { Given enough time in } \\
\text { accident and emergency } \\
\text { unit }\end{array}$ & 4.32 & 0.61 \\
& $\begin{array}{l}\text { Delay in admission to } \\
\text { ward not explained }\end{array}$ & 3.31 & 1.64 \\
& $\begin{array}{l}\text { Doctors' answers to } \\
\text { questions are clear }\end{array}$ & 4.14 & 0.52 \\
& $\begin{array}{l}\text { Nurses' answer to } \\
\text { questions are clear } \\
\text { Test results clearly }\end{array}$ & 4.75 & 0.48 \\
& 3.70 & 1.49 \\
\hline
\end{tabular}

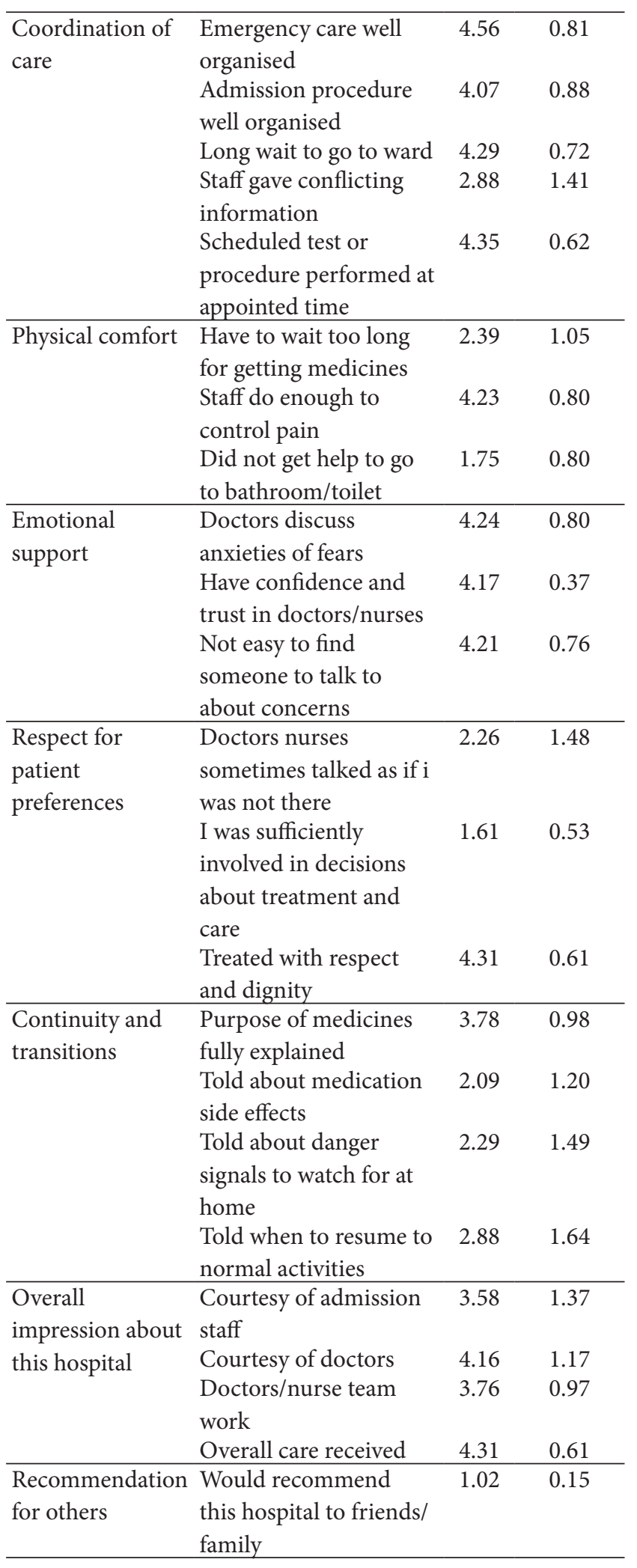


Need for evaluation of patient experiences is worry about the issues confronted amid patient fulfillment overview has prompted to an accentuation of measuring patient satisfaction 33,3 . So, now hospitals are asking patients to report in insight about their encounters of specific services, hospital episode, general practice and even about physicians rather than requesting that patients assess their care by and large classes (e.g.: excellent, very good, good, fair, poor) 月.

\subsection{Patient Experience and Patient Satisfaction}

When patient experience is viewed from the context of patient satisfaction, it is defined as the recipient's reaction to the notable parts of the specific situation and prepare and the consequences of their administration

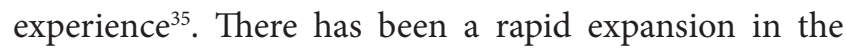
use of the term 'patient experience' in past few days, both in clinical practice and research. So, there is a rising acknowledgement, which has taken patient experiences to top priority for healthcare leaders. Patient experiences serves as a key feature for many healthcare organization, for quality improvement measures in many healthcare delivery systems

Hospitals which compete for good and paying customers have strong commercial reason for obtaining patient's feedback about satisfaction on their experience with the hospital products and services and acing on those results obtained The physical environment affects patient satisfaction and improves the personal satisfaction for patient while they stay in hospitals. The experience patient has in hospital has an effect on mental and physical health of patient. So, the better the experience, the better will be the patient satisfaction

\section{Methods}

The research design is descriptive in nature. Primary data was collected from patients in public hospitals in Chennai through administering questionnaire. The questionnaire consisted factors like, patient experience on information and education given in hospitals, coordination of care in hospitals, physical comfort in hospitals, emotional support available in hospitals, respect for patient preferences, continuity of care and transition and overall impression of patient on hospital. The study concentrates on the patient experience and their satisfaction level with respect to the above mentioned factors. 150 questionnaires were distributed out of which 117 were usable. Reliability test was done which gave a Cronbach's Alpha value of 7.08. Questionnaire was adapted from previous study ${ }^{3}$ which was modified suitably for this current study. Statistical analysis used for the study was One Way ANOVA by which hypotheses were tested.

\subsection{Hypotheses}

For studying patient satisfaction through patient experience with respect to their gender and age, the following hypotheses were formulated and tested:

$\mathrm{H}_{1}$ : There is significant positive relationship between gender and patient experience on information and education given in hospital.

$\mathrm{H}_{2}$ : There is significant positive relationship between gender and patient experience on coordination of care in hospital.

$\mathrm{H}_{3}$ : There is significant relationship between gender and patient experience on physical comfort in hospitals.

$\mathrm{H}_{4}$ : There is significant relationship between age and patient experience on emotional support received in hospitals.

$\mathrm{H}_{5}$ : There is significant relationship between age and patient experience on respect for patient preferences in hospitals

\section{Analysis}

\subsection{Hypotheses Testing}

Table 3. H1: Gender and patient experience on information and education given in hospitals

\begin{tabular}{lcccc}
\hline Gender & Mean & SD & F value & P value \\
\hline Male & 20.87 & 3.08 & 17.989 & .000 \\
Female & 18.11 & 2.56 & & \\
\hline
\end{tabular}

\begin{tabular}{lccccc}
\hline & $\begin{array}{c}\text { Sum of } \\
\text { squares }\end{array}$ & Df & $\begin{array}{c}\text { Mean } \\
\text { square }\end{array}$ & F & Sig \\
\hline Between Groups & 158.977 & 1 & 158.977 & 17.989 & .000 \\
Within Groups & 1016.322 & 115 & 8.838 & & \\
Total & 1175.299 & 116 & & & \\
\hline
\end{tabular}

Based on the $\mathrm{P}$ value which is less than 0.05 the null hypothesis is rejected at $5 \%$ level of significance. Hence it is concluded that there is significant positive relationship between gender and patient experience on information and education given in hospital. Based on the mean 
score male respondents have satisfactory experience on information and education received in the hospitals.

Table 4. H2: Gender and patient experience on coordination of care in hospitals

\begin{tabular}{|c|c|c|c|c|c|c|}
\hline Gender & Mean & SD & \multicolumn{2}{|r|}{ F value } & \multicolumn{2}{|l|}{$P$ value } \\
\hline Male & 19.63 & 3.09 & \multicolumn{2}{|r|}{12.492} & .001 & \\
\hline \multirow[t]{2}{*}{ Female } & 22.00 & 2.88 & & & & \\
\hline & & $\begin{array}{l}\text { Sum of } \\
\text { squares }\end{array}$ & Df & $\begin{array}{c}\text { Mean } \\
\text { square }\end{array}$ & $\mathrm{F}$ & Sig \\
\hline \multicolumn{2}{|c|}{ Between Groups } & 116.331 & 1 & 116.331 & 12.492 & .001 \\
\hline \multicolumn{2}{|c|}{ Within Groups } & 1070.900 & 115 & 9.312 & & \\
\hline \multicolumn{2}{|l|}{ Total } & 1187.231 & 116 & & & \\
\hline
\end{tabular}

As $\mathrm{P}$ value is less than 0.05 the null hypothesis is rejected at $5 \%$ level of significance. Hence it is concluded that there is significant positive relationship between gender and patient experience on coordination of care in hospital. Based on the mean score female respondents have satisfactory experience on coordination of care in the hospitals.

Table 5. H3: Gender and patient experience on physical comfort in hospitals

\begin{tabular}{|c|c|c|c|c|c|c|}
\hline Gender & Mean & SD & & F value & $P$ value & \\
\hline Male & 8.26 & 0.84 & & 8.401 & .004 & \\
\hline \multirow[t]{2}{*}{ Female } & 8.77 & 0.64 & & & & \\
\hline & & $\begin{array}{l}\text { Sum of } \\
\text { squares }\end{array}$ & Df & $\begin{array}{c}\text { Mean } \\
\text { square }\end{array}$ & $\bar{F}$ & Sig \\
\hline \multicolumn{2}{|c|}{ Between Groups } & 5.426 & 1 & 5.426 & 8.401 & .004 \\
\hline \multicolumn{2}{|c|}{ Within Groups } & 74.267 & 115 & 0.646 & & \\
\hline \multicolumn{2}{|l|}{ Total } & 79.692 & 116 & & & \\
\hline
\end{tabular}

Since P value is less than 0.05 the null hypothesis is rejected at $5 \%$ level of significance. Hence it is concluded that there is significant relationship between gender and patient experience on physical comfort in hospitals. Based on the mean score female respondents have satisfactory experience on physical comfort in the hospitals.

Table 6. H4: Age and patient experience on emotional support

\begin{tabular}{lcccc}
\hline Age & Mean & SD & F value & P value \\
\hline 26-40 years & 14.00 & .00 & 29.255 & .000 \\
41-55 years & 12.42 & 1.10 & & \\
56-70 years & 12.00 & 1.01 & & \\
Above 70 years & 13.00 & .00 & & \\
\hline
\end{tabular}

\begin{tabular}{lccccc}
\hline & $\begin{array}{c}\text { Sum of } \\
\text { squares }\end{array}$ & Df & $\begin{array}{c}\text { Mean } \\
\text { square }\end{array}$ & F & Sig \\
\hline Between Groups & 60.850 & 3 & 20.283 & 29.255 & .000 \\
Within Groups & 78.346 & 113 & 0.693 & & \\
Total & 139.197 & 116 & & & \\
\hline
\end{tabular}

Since $\mathrm{P}$ value is less than 0.05 the null hypothesis is rejected at $5 \%$ level of significance. Hence it is concluded that there is significant relationship between age and patient experience on emotional support received in hospitals. Based on the mean score respondents between the age group of 26-40 years have satisfactory experience on emotional support received in the hospitals.

Table 7. H5: Age and patient experience on respect for patient preferences

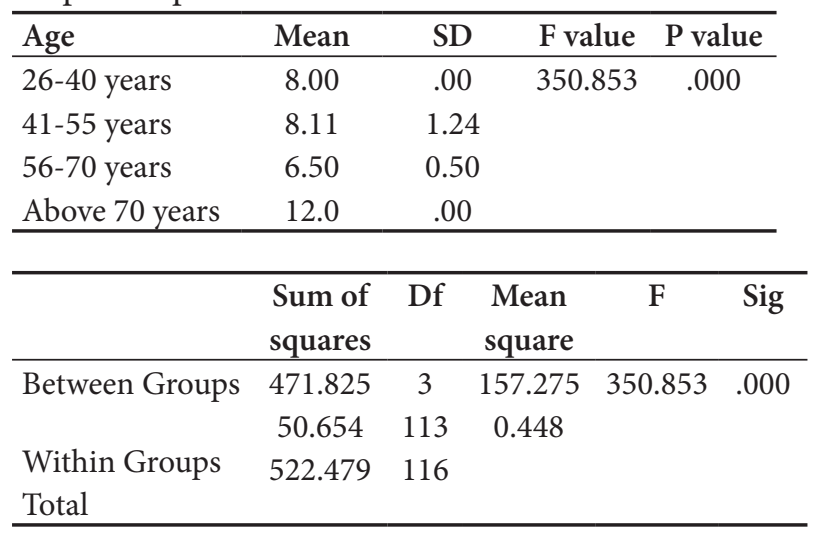

Since $\mathrm{P}$ value is less than 0.05 the null hypothesis is rejected at $5 \%$ level of significance. Hence it is concluded that there is significant relationship between age and patient experience on respect for patient preferences in hospitals. Based on the mean score respondents above a70 years have satisfactory experience on respect for patient preferences in the hospitals.

\section{Results}

There were 117 respondents for analysis. The descriptive statistics and the summary description of the survey are shown in first two tables. The mean scores including the composite indices range between 4 and 2 .

\section{Discussion}

The reason for this study is to explore how patient 
experience affects patient satisfaction. All the variables are statistically significant and positively related. The results shows that patient experience on information and education received in hospital is far more influential than others with a mean score of 20.23 , followed by patient experience on coordination of care (20.17), emotional support 12.63), continuity and transition (11.06), physical comfort (8.19). There is significant positive relationship between gender and patient experiences on information and education received from hospital, with male respondents with high satisfaction experience, while gender also exhibits a positively significant relationship towards coordination of care in hospitals, with female respondents with high satisfactory experience on it. There is significant relationship between gender and patient experience on physical comfort, with female respondent being more satisfied. Age has significantly positive relationship with patient experiences on emotional support received in hospitals, with respondents between the age group of 26-40 years being highly satisfied with their experience on emotional support. Age also has significant relationship with patient experience on respect for patient preferences in hospitals with patients above 70 years having more satisfactory experience.

\section{Conclusion}

The results o the study revealed that both gender and age has positively significant relationship with the variable of patient experiences such as information and education, coordination of care physical comfort, emotional support, and respect for patient preferences, continuity, and transmission. It was also found that patient with good and satisfactory experience in the hospital is ready to recommend the hospital to others for services. Based on the results, the hospital administrators are very much encouraged to concentrate on making strides towards the respect and importance given for patient's preferences and physical comfort of the patient, to increase patient satisfaction in future.

\section{Limitations and Suggestions}

This study expands our understanding regarding the effect of patient experiences on patient satisfaction and patients' intention to recommend the hospital to others based on their experience. However, there are some limitations. First, this study utilized only inpatients of the hospitals. Second, this study utilized only public hospitals in Chennai. Thus the generalisability of the study may still be limited. Many comparable studies in the other areas would increase the generalisability of the findings of this study. Third, there would be more scope for this study for new research findings, when carried out in private hospitals also.

\section{Reference}

1. Moon WH, Park HS. Reuse Intention Associated with the Selection Factors and Satisfaction: Focused on Spine Specialty Hospitals in Korea, Indian Journal of Science and Technology. 2015; 8(26):1-7.

2. Jenkinson C, Coulter A, Bruster S, Richards N, Chandola T. Patients' Experiences and Satisfaction with Health Care: Results of a Questionnaire Study of Specific Aspects of Care, Qual Saf Health Care. 2002 Dec; 11(4):335-9.

3. Catchpole Cited in Department of Health Human Factors Reference Group Interim Report: 1 March 2012, National Quality Board. Date accessed: 01/03/2012. Available at: http://www.england.nhs.uk/ourwork/part-rel/nqb/ag$\mathrm{min} /$.

4. Bleich SN, Özaltin E, Murray CJL. How does Satisfaction with the Health-Care System Relate to Patient Experience, Bulletin of the World Health Organization. 2009; 87(4):4.

5. The Measurement of Health Care Performance: A Primer from the CMSS. Council of Medical Specialty Societies. USA: United Health Services Inc. Ad. www.icrc.org/healthcare-in-danger:2007.

6. Patients First and Foremost: the Initial Government Response to the Report of the Mid Staffordshire, NHS Foundation Trust Public Inquiry. Department of Health, London: Stationary Office. Date accessed: 03/2013. https:// www.gov.uk/government/uploads/system/uploads/attachment_data/file/170701/Patients_First_and_Foremost.pdf.

7. Francis R. Report of the Mid Staffordshire NHS Foundation Trust Public Inquiry. London: Stationary Office; 2013.

8. Beattie M, Douglas J, Murphy M, Atherton I, Lauder W. Instruments to Measure Patient Experience of Healthcare Quality in Hospitals: A Systematic Review, Systematic Review. 2015; 4(97):1-65.

9. Coulter A, Fitzpatrick R, Cornwell C. Measures of Patients' Experience in Hospital: Purpose, Methods and Uses, The Point of Car., The King's Fund, 2009, p.8.

10. Wensing M, Elwyn G. Research in Patients' Views in the Evaluation and Improvement of Quality of Care, Quality Safe Health Care. 2002; 11:153-7.

11. Garratt A. National And Cross-National Surveys of Patient Experiences: A Structured Review, Norwegian Knowledge Centre for the Health Services. 2008; 7:1-71. 
12. Schoen C, Osborn R, Huynh PT. Taking the Pulse of Health Care Systems: Experiences of Patients with Health Problems in Six Countries, Health Affairs. 2005; 5:509-25.

13. Hekkert KD, Cihangir S, Kleefstra SM. Patient Satisfaction Revisited: A Multilevel Approach, Social Science Medical (Prospective Cohort; 20 Hospitals). 2009; 69(1):68-75

14. Dutta S, Abbas SU. HCAHPS and the Metrics of Patient Experience: A Guide for Hospitals and Hospitalists, Hospital Medicine Practice, 2015; 3(6):1-6.

15. Otani K, Patrick A, Herrmann H. Richard S, Kurz K. Improving Patient Evaluation of Hospital Care and Increasing their Intention to Recommend: Are they the Same or Different Constructs? Health Services Management Research. 2010; 23(2):1-45.

16. Ford RC, Bach SA, Fottler MD. Methods of Measuring Patient Satisfaction in Health Care Organizations, Health Care Management Rev. 1997; 22(2):74-89.

17. Eisenberg B. Customer Service in Healthcare: A New Era, Hosp Health Service Administration. 1997; 42(1):17-31.

18. Williams B. Patient Satisfaction: A Valid Concept? Social Science Method. 1994; 38(1):509-16.

19. Lynn J, Schall MW, Milne C. Nolan KM, Kabcenell A. Quality Improvements in End-Of-Life Care: Insights from Two Collaborative, Journal of Quality Improvement. 2000; 26(5):254-67.

20. Morrison RS, Siu AL, Leipzig RM, Cassel CK, Meier DE. The Hard Task of Improving the Quality of Care at the End-OfLife, Archives of Internal Medicine. 2000; 160(6):743-47.

21. De L, Rootman I. Physician Role Performance and Patient Satisfaction, Social Science Medicine. 1976; 10(1):29-31.

22. Aiello A, Fu L, Miseta A, Sipos K, David M, Bedwell B. The Ca2+ Homeostasis Defects In: A pgm $2 \Delta$ Strain of S. cerevisiae Are Caused by Excessive Vacuolar Ca2+ Uptake Mediated by the Ca2+-ATPase Pmc1p, JBC Papers in Press. Published on as Manuscript M400833200. 2003, 279, p. 38495-502.

23. Varghese J. A Study to Assess the Patient Satisfaction with Quality Nursing Care in Neuro Medical Unit, Institute of Medical Sciences and Technology Medical College. 2009; 35(2):422-29.

24. Lyngkhoi R, Brindha G. A Study on Patient Satisfaction of Outpatient Department, Indian Journal of Science and Technology. 2015; 8(32):1-5.

25. Beckman HB, Markakis KM, Suchman AL. The Doctor-Patient Relationship and Malpractice. Lessons from Plaintiff Depositions, Archeyology International Medical. 1994; 154(12):1365-70.
26. Manary MP, Boulding W, Staelin R. The Patient Experience and Health Outcomes, National England Journal of Medicals. 2013; 368(3):201-03.

27. Vadhana M. Assessment of Patient Satisfaction. In: An Outpatient Department of an Autonomous Hospital In Phnom Penh, Cambodia, Asia Pacific University, 2012, p. 1-97.

28. Jackson JL, Chamberlin J, Kroenke K. Predictors of Patient Satisfaction, Social Science of Medical. 2001; 51(2):609-20.

29. Zhang Y, Rohrer J, Borders T. Patient Satisfaction, Self Rated Health Status and Health Confidence: An Assessment of the Utility of Single-Item Questions, American Journal of Medical Quality. 2007; 22(1):42-9.

30. Clayton CM, Grossman JH, Hwang J. The Innovator's Prescription: A Disruptive, Solution for Health Care. 2010; 4(1):164-201.

31. Youn I, Kim S, Hyeon LY, Seok LY, Chung HT. A Study on the Effects of Risk and Uncertainty of Information on Service Quality Assessment with Focus on Cancer Patients' Cases, Indian Journal of Science and Technology. 2016; $9(26): 1-7$

32. Department of Health Equity and Excellence: Liberating the NHS. Date accessed: 2010. Available at: www.icrc.org/ health-care.

33. Cleary PD, Edgman-Levitan S, McMullen W, Delbanco TL. The Relationship between Reported Problems and Patient Summary Evaluations of Hospital Care, Quality Review Bulletin, 1992; 18(2):53-9.

34. Cleary PD. Satisfaction may not Suffice! A Commentary on A Patient's Perspective, International Journal of Technology Assessment in Health Care. 1998; 15(1):35-7.

35. Pascoe GC. Patient Satisfaction in Primary Health Care: A Review and Analysis, Evaluation of Program Planning. 1983; 6(3-4):185-210.

36. Apfelbaum JLC, Chen SS, Mehta M, Anesthesia A, Analgesia A. Hospital-based Patient Experience and Satisfaction Survey, Hospital Authority. 2013; 97(2):534-40.

37. Draper M, Cohen P, Buchan H. Seeking Consumer Views: What use are Results of Hospital Patient Satisfaction Surveys? International Journal for Quality in Healthcare. 2001; 13(6): 463-68.

38. Easy F, Naseri G. A Study on the Effect of the Components of Physical Environment on Patient Satisfaction in Drug Rehabilitation Centers, Indian Journal of Science and Technology. 2015; 8(28):1-8.

39. Yu-Chuan Y. The Picker Institute Implementation Manual, Boston, MA: Picker Institute, 1999; 14(5):353-58. 